\title{
Meet the candidates for ALA President Vote in the election this spring
}

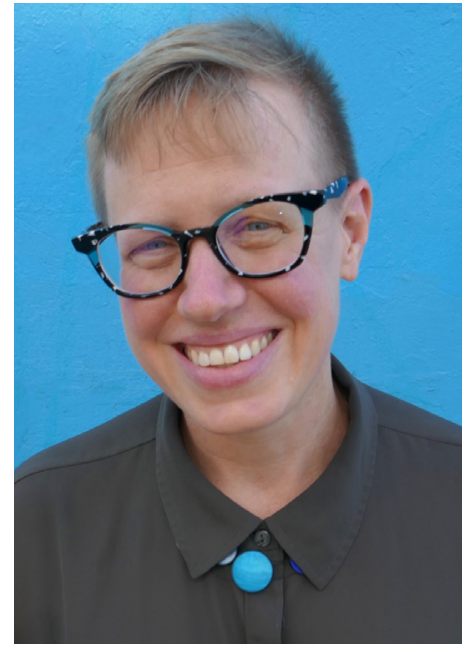

Emily Drabinski

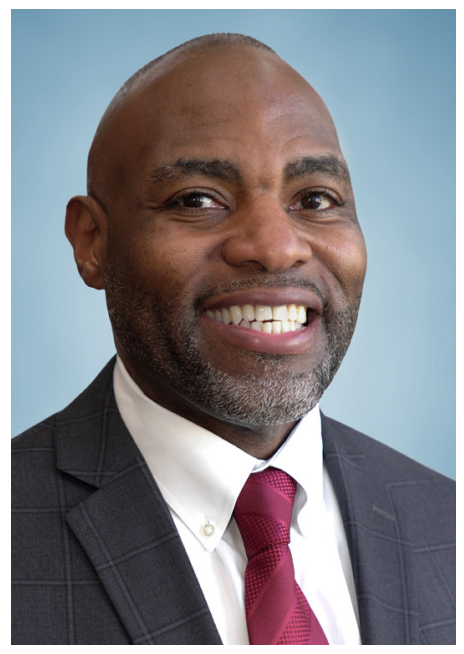

Kelvin Watson

The ACRL Board of Directors posed the following questions to the candidates for ALA president, and $C \mho R L$ News is pleased to publish their responses. Each candidate was given 1,500 words to respond to six questions and contribute an optional opening statement. The responses are identified under each question.

\section{Opening statements}

Emily Drabinski: So many of us find ourselves at the ends of our worlds. The consequences of decades of unchecked climate change, class war, white supremacy, and imperialism have led us here. If we want a world that includes public goods like the library, we must organize our collective power to fight for those priorities. ALA offers us a set of tools that can harness our energies and build those capacities. I am honored to stand for election as president of this association. In this role, I will steward our shared resources on behalf of all of us who seek a better, more equitable, and more just world. I know that world is possible, and I want to build it with you. I am humbled to ask for your vote.

I have been a member of ALA since I began my career. I served one term as ALA councilor at- large and one as chair of the International Relations Committee. As an academic librarian, ACRL has served as my divisional home for the last 20 years. My work has included chairing the Information Literacy Frameworks and Guidelines Committee, co-chairing the ACRL President's Program Committee, serving as a reviewer for the biannual conference, and editing the reviews section of College \& Research Libraries. I am an active scholar and publish and present widely on topics related to knowledge organization, information literacy, 
and critical librarianship. If elected, the concerns of academic library workers and organizations will continue to be central to my vision.

Kelvin Watson: Kelvin Watson is executive director of the Las Vegas-Clark County Library District. He brings deep experience in fundraising, technology, program development, and demonstrated success in addressing the digital divide to his leadership roles, meeting people "where they are," with initiatives targeting non-traditional library users. One recent example is a partnership with the RTC of Southern Nevada, which provided bus riders with digital access to the library through onboard WiFi. At Broward County Libraries, he brought transformative change through similar collaborative partnerships and ambitious, groundbreaking initiatives, such as streamlining access to resources, and introducing new technology. As chief operating officer for Queens Library, he was instrumental in establishing several groundbreaking programs, and developing and implementing digital divide strategies, promoting equality and equity for all.

\section{As the future ALA president, tell us what you know about ACRL's Core Commit- ment to Equity, Diversity, and Inclusion (EDI). Can you share your specific partner- ship ideas that advance ACRL's Core Commitment and expand membership for both ACRL and ALA?}

Drabinski: ACRL has made significant and meaningful strides toward putting equity at the center of our work together. Significantly, EDI principles have been embedded at every level of the organization as members are expected to include goals and objectives related to this core commitment in our plans. As ALA president, my approach would be twofold. First, we need to listen to our members, especially our members whose interests have historically not been at the center of our work. We need to find out if our members know what we are doing and whether they believe that our work is enough. Is it what library workers need? How might our work become more targeted to address specific needs of specific groups? And are other parts of the profession doing EDI work better than ACRL or the ALA? Second, we must communicate to members how the Core Commitment is operationalized within the association and made relevant to their experiences in ACRL and ALA. This means sharing information with members where they are, online and in person, one on one and in small groups. We need more conversations across the library ecosystem. As ALA president, I will bring an organizing and mobilizing approach to the work, finding ways to engage members across the association and division as well as colleagues who have long offered models of meaningful advocacy and organizing work, particularly the National Associations of Librarians of Color (AILA, APALA, BCALA, CALA, REFORMA, and JCLC).

Watson: The fact that ACRL leadership has made a strong, public commitment to real change around equity, diversity, and inclusion is a significant achievement for the organization holistically. We have all been aware in this profession of the long-standing inequities that have existed, and I respect and applaud ACRL members calling for concrete change. I am very impressed by the specificity of ACRL's Plan for Excellence/Core Commitment, particularly in "developing inclusive organizations, spaces and services; guarding against policies and practices that intentionally or unintentionally create racial inequalities; [and] embodying diversity in the profession." If ACRL can make measurable strides in these 
areas, their blueprint will be an inspiration throughout ALA. As president, I will also bring successful programs from my leadership roles at Queens Library, Broward County Libraries (BCL), and now at the Las Vegas-Clark County Library District (LVCCLD). I have a proven track record in powerful public/private partnerships and collaborations, and I am already putting these to work by exploring ways to help fund initiatives that support our members.

\section{How will you assess the impact of the changes from the Midwinter Meeting to LibLearnX on ALA membership?}

Drabinski: ALA is in the midst of significant transformation in the areas of governance structure, operating agreements, and revenue streams. LibLearnX represents one of those shifts. Potential impacts include an expansion of access to power through the use of online tools for governance and to process meetings and an increase in value to members who can meet to learn and grow together at a smaller footprint event. Data will be crucial to any assessment of these changes. We must pay close and critical attention to the numbers: who and how many attend, and what sessions are the drivers of engagement. And as long as conferences remain crucial to ALA's financial viability, we must attend to the bottom line. But we also need to connect with our members directly, acknowledging that numbers rarely tell the entire story. We should use these changes as opportunities to engage ALA members and non-members alike in face-to-face conversations about what we want and expect from our professional association. I would like to form focus groups of library workers and find out from them what they want and need from our summer and winter events.

Watson: There was almost a perfect storm of challenges during the new Midwinter LibLearnX Meeting format, which included budget constraints, competition with PLA attendance, and a key speaker who didn't allow for advance public relations. Before we make decisions on how to move forward, we must first gather data and evaluate from a 360-degree perspective: Did Zoom fatigue contribute to lower attendance? Did the technology function well? Were there competing library industry events? What can we learn from social media comments around the event? Did the pandemic play a role? Should we explore smaller regional meetings to reduce travel expense and COVID exposure? We are seeing an increase in student engagement, which is critical to ALA's future. Can we further grow student attendance by diversifying speakers and workshops to include other specialties that support libraries, such as technology, marketing, education, and the fine arts? This could also attract attendees from these areas by marketing directly to them.

3. Please share your thoughts about supporting equity, diversity, inclusion, and accessibility in libraries. Describe steps you have taken to ensure that these fundamental principles have moved from idea into practice.

Drabinski: Equity work has been at the center of my academic library work and scholarship since I began leading library tours for undergraduates at Sarah Lawrence College in 2004. My research has explored the politics of knowledge organization systems, particularly the ways we organize and describe LGBTQIA+ materials. I have written and presented widely on these topics and have also built platforms for the exploration of gender and sexuality issues in librarianship through a book series and 
colloquia on these topics. I took on the role of reviews editor for College \& Research Libraries in 2020 with the express intention of diversifying the field of reviewers. You can see the fruits of that commitment in the pages of the journal. As a library director, my focus has been on expanding opportunities for BIPOC individuals in my organization, using the tools of contract enforcement to ensure that everyone in my library has access to the rich opportunities a career in academic libraries afford. My intellectual interests have always been about the place where rubber hits the road, and that is where I practice my library craft, as well.

Watson: The digital divide is one of the most serious deficiencies in the American education system, and as ALA president, I will work to harness funding from the Congressional Build Back Better Plan to tackle this crisis and its negative effects on equity, diversity, inclusion and accessibility in our communities. We must invest in proven strategies, and I will ask all ALA members to share with me their unique solutions to the challenges that we all face. Leading by example, I would like to share some of my past and current model programs:

- At BCL, I obtained more than $\$ 200,000$ in grant funds to provide iPads for K-3rd grade students from low-income households, enabling remote access to ebooks and participation in the summer reading program.

- Two additional grant-funded projects at BCL supported workers displaced by the pandemic. The program provided jobseekers with Chromebooks and tablets, enabling them to search for jobs, participate in online interviews, access educational programs, including an online high school diploma and career certification program, and more.

- Through a community partnership with the Dan Marino Foundation, BCL provided access to Virtual Interactive Training Agent (VITA), a web-based virtual reality system that helps young adults with autism spectrum disorder and other developmental disabilities prepare for job interviews.

- I introduced the JAWS (Job Access With Speech) screen reader software on public-use computers at 20 BCL library locations. JAWS was developed for visually impaired computer users who are unable to see screen content or navigate with a mouse. It provides speech for popular PC applications, allowing users to search the Internet, write a document, read an email, and create presentations. JAWS also allows all major Microsoft functions to be controlled with keyboard shortcuts and spoken feedback.

- While at LVCCLD, I have been working to expand our teen tech initiatives such as the Best Buy Teen Tech Center, a partnership with Best Buy to create hands-on technology training in a fun, relaxed, lounge environment, where teens can explore and master in-demand digital skills for 21 st-century jobs. Our tech centers work to bridge the digital divide by giving youth in low-income neighborhoods free tech education and tutoring with local university students, to help to build confidence and envision a future where college is attainable.

- Another new LVCCLD initiative I am implementing is funded by the "Supporting Advancing Nevada's Dislocated Individuals" grant—a partnership with the Nevada Governor's Office of Workforce Innovation and the Nevada State Library - designed to help individuals re-imagine their career development. The project develops digital knowledge in healthcare, advanced manufacturing, logistics, IT, and the construction trades. Enhanced features of the project include career navigation that helps identify and build skills, and awards college 
credits and competency badges. The project will use virtual reality and 3-D training for jobs within Nevada's resilient STEM industries.

High-quality tech projects like these, delivered through libraries, give communities access and hope to retool and re-imagine. This is the vision and leadership I will bring to the ALA platform as president.

\section{ALA and ACRL must demonstrate their value to recruit, engage, and retain their membership. How can ALA remain a relevant, vital, and financially sustainable as- sociation to academic and research librarians? To those new to the profession?}

Drabinski: We need to be consistently engaged in small and large ways with listening to the library workers who make up our association and division. What do our colleagues want from professional groups like ours? What are we doing that works and where are we missing the mark? I believe that membership should be accessible to all library workers in every income bracket, and as president I will work to assess and possibly rethink our current sliding scale with this goal in mind. Furthermore, I'd like to make opportunities to shape demands, make decisions, and direct resources available to all, not only the select few who can be slotted into existing committee structures. Library issues should be connected to broader public conversations about the value of higher education and the importance of public investments in scientific research, the humanities, and the arts. All members should have the opportunity to learn and practice organizing skills necessary for building institutional power within ALA and ACRL and in their workplaces and communities.

Watson: A significant way to expand membership in ACRL and ALA is to elevate careers for paraprofessionals and support staff by changing the way we staff our libraries. We should consider the larger needs of the organization and what skills are needed to assist our paraprofessionals. There are many professions that can enhance the mission and value of community libraries, such as web developers, schoolteachers, social workers, nurses, graphic designers, and generally anyone skilled in the STEAM categories. I believe the focus and emphasis should be on the position's needs, actual work, and leadership. For example, there are schoolteachers with Master's or Doctorate degrees and years of classroom experience whose skills would be invaluable to libraries. However, because they do not have an MLS or MLIS degree, they are not considered for librarian positions. Social workers are a great example of specialized training that libraries are beginning to seek out. They are not librarians, but their expertise is critically needed.

5. As the future ALA president, what unique leadership challenges might you face when communicating the value of a membership organization during a pandemic? In this context, what does a successful term as ALA president look like to you?

Drabinski: A wealth gap that has never been wider, climate disaster all around us, the massive disinvestment in public institutions and supports, this is our present reality. Now is the time for those who share these commitments to work together for a better future. As president, I will find ways to build on an affirmative vision that equips all of us with the skills necessary to make that vision real. I would count my term a success if more of us talked to each other than did this year, and if we used our time together to shape demands, plan campaigns, build our power, and raise the visibility of library workers in conversations about the public good. That means using existing ways of connecting members to each 
other-conferences, committees—and finding new ways — focus groups, office hours - to produce conversations that can define problems and work toward solutions.

Watson: ALA continues to assist and guide through these unparalleled times, providing leadership through advocacy and partnerships that support all libraries and communities, while balancing the internal opportunities for change that the pandemic has brought.

For me, leadership and communication during the new normal of the pandemic, is all about increasing engagement, taking concrete action, and delivering results.

As president, I will focus on the accountability and performance that I demand of myself. We must deliver on what we promise and build upon this unique moment in time to revitalize our mission and service. We must remain agile during this unpredictable period in our nation's history, while forging ahead, undeterred.

A successful ALA presidency means a fundamental transformation of our engagement, inclusivity, and our approach to advocacy. We must ask ourselves every day, what else should we be doing to advance the ALA mission? What national leaders and influencers need to know how libraries change lives? What new funding sources can we tap, in order to fund real change? All of these questions will help to drive expanded services, training, and attract a diverse membership. It will also, in turn, allow us to be intentional and strategic in serving underserved populations and developing impactful resources in concert with our business partners. I call on all ALA members to envision where we must be in the future and to join me in achieving these goals.

\section{What does "One ALA" mean to you? How do you see ACRL and other divisions working together to advance ALA's future?}

Drabinski: One ALA is at the heart of the association's Pivot Strategy, central to its vision of a transformed organization. It means leveraging the strengths of the entire library ecosystem to build an association that can respond nimbly and with the backing of a large and growing membership to challenges that range from attempts to remove books from a middle school library to a scholarly communication landscape that locks academic libraries into unsustainable contracts with profit-extracting publishers. Any pivot like this one requires trust. Trust requires robust and transparent communication and a meaningful commitment to democratic decision making. These are my priorities as a library worker, community member, and parent, and would be at the center of my leadership.

Watson: One strong ALA means an ecosystem that is inclusive of all types of libraries and financially viable. We need to increase our professional/leadership development, eliminate duplication, and empower each division, roundtable, and committee. We also need to support and advocate for each member and the profession. An example includes public and academic support and advocacy of the importance of K-12 school libraries. I am a true believer in the power of raising one voice in solidarity for a great cause, and we can do this while still balancing the unique needs and diverse expertise of all ALA members. This is the same philosophy we use in managing branches in a large library system-there is competition, debate, challenges, and successes, but regardless of the path, all branches are unified on one journey. $n$ 